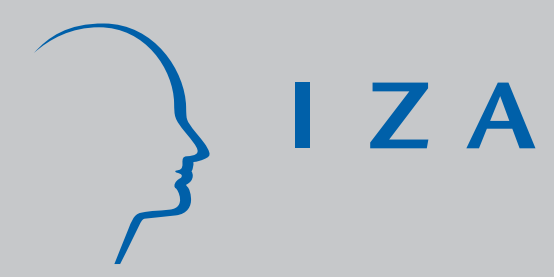

IZA DP No. 3381

A Theory of Efficiency Wage with Multiple Unemployment Equilibria: How a Higher Minimum Wage Law Can Curb Unemployment

Kaushik Basu

Amanda J. Felkey

March 2008 


\title{
A Theory of Efficiency Wage with Multiple Unemployment Equilibria: How a Higher Minimum Wage Law Can Curb Unemployment
}

\author{
Kaushik Basu \\ Cornell University and IZA \\ Amanda J. Felkey \\ Lake Forest College \\ Discussion Paper No. 3381 \\ March 2008 \\ IZA \\ P.O. Box 7240 \\ 53072 Bonn \\ Germany \\ Phone: +49-228-3894-0 \\ Fax: +49-228-3894-180 \\ E-mail: iza@iza.org
}

Any opinions expressed here are those of the author(s) and not those of IZA. Research published in this series may include views on policy, but the institute itself takes no institutional policy positions.

The Institute for the Study of Labor (IZA) in Bonn is a local and virtual international research center and a place of communication between science, politics and business. IZA is an independent nonprofit organization supported by Deutsche Post World Net. The center is associated with the University of Bonn and offers a stimulating research environment through its international network, workshops and conferences, data service, project support, research visits and doctoral program. IZA engages in (i) original and internationally competitive research in all fields of labor economics, (ii) development of policy concepts, and (iii) dissemination of research results and concepts to the interested public.

IZA Discussion Papers often represent preliminary work and are circulated to encourage discussion. Citation of such a paper should account for its provisional character. A revised version may be available directly from the author. 


\begin{abstract}

\section{A Theory of Efficiency Wage with Multiple Unemployment Equilibria: How a Higher Minimum Wage Law Can Curb Unemployment ${ }^{*}$}

This paper uses efficiency wage theory and the existence of community-based sharing to hypothesize that labor markets in developing countries have multiple equilibria - the same economy can be stuck at different levels of unemployment with different levels of wages. The model is meant for developing economies where wage-productivity links are discernible and income-sharing among the poor is prevalent. It seems reasonable to posit that in such an economy more unemployment leads to more income sharing. The main results are generated combining this claim with a theoretical demonstration of the fact that more sharing increases unemployment rates. As corollaries, we show that (1) within the same society, two different racial groups that may be ex ante identical can have different levels of unemployment and wages in equilibrium and (2) the imposition of a legal minimum wage can raise employment.
\end{abstract}

JEL Classification: J60, O12, D40

Keywords: unemployment, efficiency wage, minimum wage law, racial differences, South Africa

Corresponding author:

Kaushik Basu

Department of Economics

Cornell University

Ithaca, New York 14853

USA

E-mail: kb40@cornell.edu

\footnotetext{
*For comments and suggestions we are grateful to Abhijit Banerjee, Ashok Guha, Rune Hagen, Louis Hotte, Arun Kumar, Anjan Mukherji, Ted O'Donoghue, Utsa Patnaik, Anna Paulson and the participants of the Theoretical Works-in-Progress Seminar and the conference on '75 Years of Development Research', Cornell University, 7-9 May 2004, where preliminary versions of the paper were presented. The paper also benefited from seminar presentations at the Indian Statistical Institute and Jawaharlal Nehru University. Finally, we are grateful to two anonymous referees and an editor for many useful comments and suggestions.
} 


\section{Introduction}

This paper revisits an early theoretical literature concerning wage rigidity and unemployment in developing countries. Starting with the seminal work of Leibenstein (1957, 1958), there was a period of enormous research activity, which tried to explain wage rigidity and unemployment in poor economies, where a higher wage meant better nutrition and greater labor productivity. ${ }^{1}$ This literature was very influential; it triggered other explanations of involuntary unemployment, which relied on the idea of an 'efficiency' wage as epitomized in the paper by Shapiro and Stiglitz (1984), related economic research to clinical evidence on nutrition and productivity (Dasgupta and Ray, 1990; Osmani, 1990) and entered textbooks of development economics as accepted wisdom (Ray, 1998).

While this literature successfully explained wage rigidity and unemployment in developing countries, it overlooked the possibility of a multiple-equilibria result, which can have important policy implications. In this early literature a labor market in an economy typically had one equilibrium, which may be one of full employment or one in which there is involuntary unemployment. If, for instance, an economy had involuntary unemployment, then to shift the economy to full-employment or higher employment would require continuous policy intervention, whether it be a legislative measure or one involving taxes and employment subsidies or planned public sector employment.

This result changes sharply once we introduce a realistic and seemingly innocuous assumption into the above models. In much of the Leibensteinian efficiency wage models it is presumed that each worker consumes her entire wage. In reality this is

\footnotetext{
${ }^{1}$ See, for instance, Mazumdar (1959), Mirrlees (1975), Rodgers (1975), Stiglitz (1976), Bliss and Stern (1978), Agarwala (1979), Dasgupta and Ray (1986, 1987), Guha (1989), and Basu (1993).
} 
of course not true. A laborer would typically consume only a fraction of her wage-even if it were close to 1 . In itself, this would make no difference to the existing efficiency wage models, cited in footnote 1 . But suppose we assume, realistically, that the fraction that a person consumes depends on certain features of the economy, such as the level of unemployment. For instance, if unemployment increases, each worker will consume a smaller fraction of her wage, since she would typically be sharing her income with others in her community, family or caste-group, who have become unemployed. This modification paves the way for a new set of results. The same economy could now have several equilibria involving different levels of unemployment, including possibly an equilibrium with no unemployment. The standard efficiency wage model is good at explaining why economies have open unemployment with rigid wages, but it is ill-suited to explain why the same economy can over short periods of time move from one level of unemployment to another, with no visible adjustment processes at work. The present paper tries to amend this deficiency.

A result of multiple unemployment outcomes occurs in Aghion and Blanchard (1994). Their model is driven by an alternative concept of efficiency wage (one that does not affect worker productivity, which does not vary with unemployment levels in their model) and results in two unemployment equilibria but one stable and one unstable. On the other hand, our model explains the existence of multiple stable equilibria, with the important implication that government intervention may be necessary but need not be permanent. In a related paper by Aghion, Blanchard and Burgess (1994) there is the suggestion of another, more political-economy-driven argument in the context of transition economy workers. Such workers will of course have an interest in maintaining 
a low unemployment rate. The success that they have in this collective objective of theirs depends on the support that they can generate among managers by throwing their weight against restructuring plans the government may have. These blocking coalitions can be broken by other forces, giving rise to a higher level of unemployment.

Returning to the framework of our model, in the structure that we describe, there is scope for thinking of policy interventions, which entail a one-time government action (or a transitory policy intervention) to deflect the economy from one equilibrium to another. More surprisingly, it is now possible for an economy to have one equilibrium in which wages are low and unemployment high and another where wages are high with no unemployment, which has important implications for minimum-wage policy.

The model also sheds light on an inadequately understood feature of labor markets, namely the prevalence of divergent unemployment rates among groups or communities that are visibly different. Some of the most striking evidence on this comes from South Africa, where the unemployment rates across different racial groups can be widely disparate (Leibrandt et al., 2003; Casale et al., 2004). This paper helps us understand how such differences can be sustained, links these differences to other features of the economy and its racial groups, and yields testable propositions.

The next section presents some of the evidence that motivates this paper, in particular, the importance and legitimacy of the claim that people in poor countries share resources. Section 3 presents our basic theoretical model of efficiency wage with multiple equilibria in the labor market. The paradoxical result concerning minimum wage legislation follows in section 4 . Section 5 analyzes the role of government 
subsidies and how a one-period intervention can cause a permanent change in market outcomes. Section 6 concludes the paper by commenting on some policy implications.

\section{The Empirical Setting}

The mushrooming literature on efficiency wages was a response to the widely documented but poorly-understood phenomenon of open unemployment and wage rigidity. This literature explained why wages may not decline in the face of unemployment. But this literature implies that for each economy there is only one level of unemployment that can be an equilibrium. In reality, countries seem to settle into different levels of unemployment for certain stretches of time. In the US, during 1991 and 1992, the unemployment rate was almost 7.1\%, but during the years 1999 and 2000, it held steady at 3.8\%. It has risen back, again, since then.

Similarly, in societies where the labor market happens to be fragmented, one often finds large differences in contemporary unemployment rates. In South Africa, the Labor Force Survey of 2003 reports an unemployment rate of $10 \%$ for whites and 50\% for Africans (Casale et al., 2004; Stats SA, 2003). The model we develop below directly addresses the subject of different resting points as far as the rate of unemployment is concerned. In a case where the sharing of income with the unemployed happens within racial groups, one can see why different groups may settle at different equilibria. In South Africa, we know that not only do the whites have a lower unemployment, but they earn a higher wage. While wage statistics are difficult to find, one can get a sense of this from the fact that, in 2003, the monthly real income of Africans was 1,484 rands, while for Whites it was 6,372 rands. Can this be explained by the model? 
Interestingly, we will see later that the model suggests that an economy can have two equilibria: one in which there is no unemployment and wages are high and another in which there is unemployment and wages are low. While it is true that Whites in South Africa have unemployment, if we correct for the fact that the South African economy is a high-unemployment economy in general, the above numbers for Whites and Africans could be treated as a stylized empirical counterpart of this result.

Let us turn now from the implications of the model to the one new axiom that we will combine with the standard efficiency wage theory. This axiom asserts that workers do not always consume everything they individually earn, but have mechanisms for sharing and supporting the unemployed and destitute among them. This can take the form of supporting family members who happen to be unemployed but also often has a much larger reach, whereby employed people may support members of their community or village who run into hard times.

There is, fortunately, plenty of evidence that there is altruistic-income sharing that goes on in poor societies. When one person in the household becomes unemployed, others chip in and contribute to that person's consumption. As Hoff and Sen (2006, p.95) point out, 'the kin system’ may be viewed 'as a social contract of mutual assistance among members of an extended family.' Since such sharing is not confined to nuclear households, the possibility of an employer employing everybody with whom one worker shares his wage may not be a realistic assumption. This is so especially in poor economies where firms are small.

If sharing were confined to immediate family members as assumed by Genicot (2005), firms could, in principle, employ the whole unit and ensure that the wages they 
pay are entirely ploughed back into productivity from which that firm benefits. Even in this case, it is debatable whether employment of the whole family would be optimal from the firm's perspective. For one, the distribution of skill in a family may not match the skills required by the firm. Regardless, sharing has been documented to occur in much larger communities_-villagers often have informal credit arrangements available to the unemployed and sharing among ethnic groups is evidenced by the increases in remittances during bad times. So it is unlikely that firms will be able to internalize the positive externalities of sharing.

The solidarity mechanisms that evolve in communities where resources are scarce were explicitly pointed out as early as the nineteen forties by Evans-Pritchard (1940). Anthropologists were the first to pursue an explanation of this phenomenon. ${ }^{2}$ They attributed the existence of sharing to morals and ethics, or the existence of a common value system that entails the 'right to subsistence and the principle of reciprocity' (Scott, 1976; Popkin, 1979). They note the precarious nature of survival led to the formation of mechanisms by which individuals would share in order to insure against starvation. This is why evidence of solidarity mechanisms exists primarily in pre-industrial and underdeveloped economies, and only emerges in developed countries during wartime or natural disasters (Fafchamps 1992).

Economists have also found significant empirical evidence that sharing exists. Townsend (1994) notes that an optimal and fully insured arrangement for individual consumption within a village is determined as if all crop output were pooled and optimally redistributed among community members - this would be the case in which

\footnotetext{
2 See Cashdan (1985), Kent (1993), Platteau (1997), Cox et al. (1998). Bardhan (1980) and Platteau and Abraham (1987) discuss some of the importance of anthropological findings for economics.
} 
members of the village were sharing resources perfectly amongst themselves. This full insurance scheme means individual crop output would not affect individual consumption, which would therefore be entirely explained by aggregate output and individual fixed effects. Since he finds a significant co-movement between household consumption and village average consumption in three poor Indian villages, there is evidence that individuals in these communities are sharing in order to smooth income shocks. Townsend finds own income, sickness and unemployment do not significantly affect individual consumption, rather there is a remarkable ability to smooth personal consumption with informal credit markets and gifts. ${ }^{3}$

\section{A Model of Efficiency Wage with Sharing}

Our aim is to develop a model of efficiency wage where a worker's nutrition and, therefore, effective labor depends positively on the wage the worker earns. This kind of labor market modeling for developing countries has a long intellectual tradition dating back to Leibenstein (1957) and is also represented in the works of Mirrlees (1975), Stiglitz (1976) and Dasgupta and Ray (1986, 1987). However, what was overlooked in this literature and has important implications for the model is that in all societies - and maybe especially so in poor countries—small communities, households and villages have informal systems of helping out those who are unemployed and destitute.

\subsection{The Sharing Rule}

We introduce this complication by treating $\alpha \in(0,1]$ as the fraction of a person's own wage that she keeps for herself. For simplicity we assume that there are no savings in the

\footnotetext{
${ }^{3}$ For other evidence see Fafchamps and Lund (2003), Kochar (2000) and Ravallion and Dearden (1988).
} 
economy. Hence, if a person's wage is $w$, her consumption is $\alpha w$, and $(1-\alpha) w$ is what she contributes for the upkeep of those who are unemployed. Clearly, then, if $U$ is the unemployment rate in this society, we would expect $\alpha$ to depend on this. Hence, $\alpha=\alpha(U)$. In the present paper we use a very simple household model to derive this relation. Assume each household has $t$ adults and $d$ children; and each household follows the rule that all adults in the household will have the same consumption and each child will consume a fraction $\delta \in(0,1)$ of each adult's consumption. In a more sophisticated model we may allow for power play within the household with gender mattering and the breadwinner consuming more than others (Basu, 2006) but these complications are unnecessary here.

We shall in our formal model assume that (a) income sharing takes place within the household (which could be large and take the form of multiple families sharing one common kitchen, as happens often in poor regions) and (b) that the economy's total unemployment falls equitably on each household. Therefore, if $U$ is the unemployment rate in the economy, then we assume for simplicity that in each household $t U$ adults are unemployed. Hence, if the market wage is $w$ and we use $c$ to denote each adult's consumption, then it must be the case that $c t+\delta c d=(1-U) t w$. Since $c=\alpha w$, it follows that

$$
\alpha=\frac{(1-U) t}{t+\delta d},
$$

which has the property $\alpha^{\prime}(U)<0$. In other words, as employment rises, the contribution to the common welfare fund declines. Assumption (b), described above, is of course a strong assumption but it is made for algebraic simplicity. It is easy to see that the main 
results of the model would remain valid under several generalizations (including heterogeneity of unemployment across households and even heterogeneity of sharing across families). We shall later consider the case where households in different racial groups face different incidences of unemployment. More generally if we assume that, as $U$ increases, each household's expected unemployment rate rises as does the expected amount of sharing in the household, the algebra would be more complex, but our main results would be robust.

In modeling the labor market, we will assume that each agent—-that is, each laborer and each employer - treats $\alpha$ as a parameter. Of course, it is their collective behavior that finally determines $U$ and, through that, $\alpha$. But it also seems reasonable to suppose that every individual will treat the national employment rate as beyond his influence. This is in keeping with the standard assumption in competitive models that each individual treats prices as given.

\subsection{The Quasi Equilibrium}

Let us now turn to the decision problem of the firm. Following the now-standard analysis (see Basu, 1997; Ray 1998) we assume that the number of efficiency units, $h$, produced by a worker depends on the worker's consumption, $c$. In particular,

$$
h=h(c) \text {, }
$$

where $h(c)=0$, for all $c<a$ (for some $a>0$ ) and for all $c \geq a, h^{\prime}(c)>0, h^{\prime \prime}(c)<0$. In addition $h(c)$ is bounded from above. Since $\alpha \in(0,1]$ is the fraction of a person's wage that he spends on his own consumption, if he is paid a wage of $w$, then $h=h(\alpha w)$. 
Assume that in this economy, there are $N$ workers and they supply their labor inelastically. ${ }^{4}$ Also there are $m$ identical firms, each endowed with the production function:

$$
x=f(H), \quad f^{\prime}>0, f^{\prime \prime}<0
$$

where $H$ is the total amount of efficiency units of labor used by the firm and $x$ is the output. Hence, if a firm pays a wage of $w$ and employs $n$ workers, its profit is given by

$$
\pi(n, w)=f(n h(\alpha w))-n w .
$$

We take the price of the product to be 1 .

The way we develop the model is as follows. We shall first treat $\alpha$ as fixed exogenously and describe a labor market equilibrium that we shall call an ' $\alpha$-quasiequilibrium'. Hence, for every $\alpha \in(0,1]$, there will be an $\alpha$-quasi-equilibrium. We shall then look for the value of $\alpha$ that has a self-fulfilling property and use that $\alpha$ to define a (full) competitive equilibrium of the labor market.

Let us begin by working out each firm's unconstrained optimum. This is clearly given by the first-order conditions, $\frac{\partial \pi}{\partial w}=0$ and $\frac{\partial \pi}{\partial n}=0$. That is,

$$
\begin{aligned}
& f^{\prime}(n h(\alpha w)) n h^{\prime}(\alpha w) \alpha=n \\
& f^{\prime}(n h(\alpha w)) h(\alpha w)=w
\end{aligned}
$$

(5) and (6) imply

$$
\frac{h(\alpha w)}{w}=h^{\prime}(\alpha w) \alpha .
$$

\footnotetext{
${ }^{4}$ This assumption is purely for simplicity. An upward-sloping supply curve would leave our analysis unchanged.
} 
From (7), we get the ideal wage the firm would like to pay. This depends on $\alpha$. Hence we will write this as $w(\alpha)$. This is illustrated in Fig. 1. What equation (7) essentially says is that firms would like to offer wages where the average product of consumption in terms of efficiency units is maximized. Figure 1 also illustrates explicitly how sharing will affect the firm's wage choice and the efficiency units they get at a chosen wage. For any positive level of sharing $(\alpha<1)$ firms will offer a higher wage so that $h(\alpha w)$ remains constant but efficiency units per dollar $h(\alpha w) / w$ is lower than if sharing did not exist. In the Fig. 1 below, the wage, $w$, chosen by the firm will be such that $\alpha w$ is given by the point marked $k$ in the figure. So, when there is no sharing $(\alpha=1) w_{0}=k$ and when there is sharing, that is $\alpha<1$, then $w_{1}=k / \alpha$. It is immediately obvious that $w_{0}<w_{1}$-a higher wage is paid when sharing occurs.

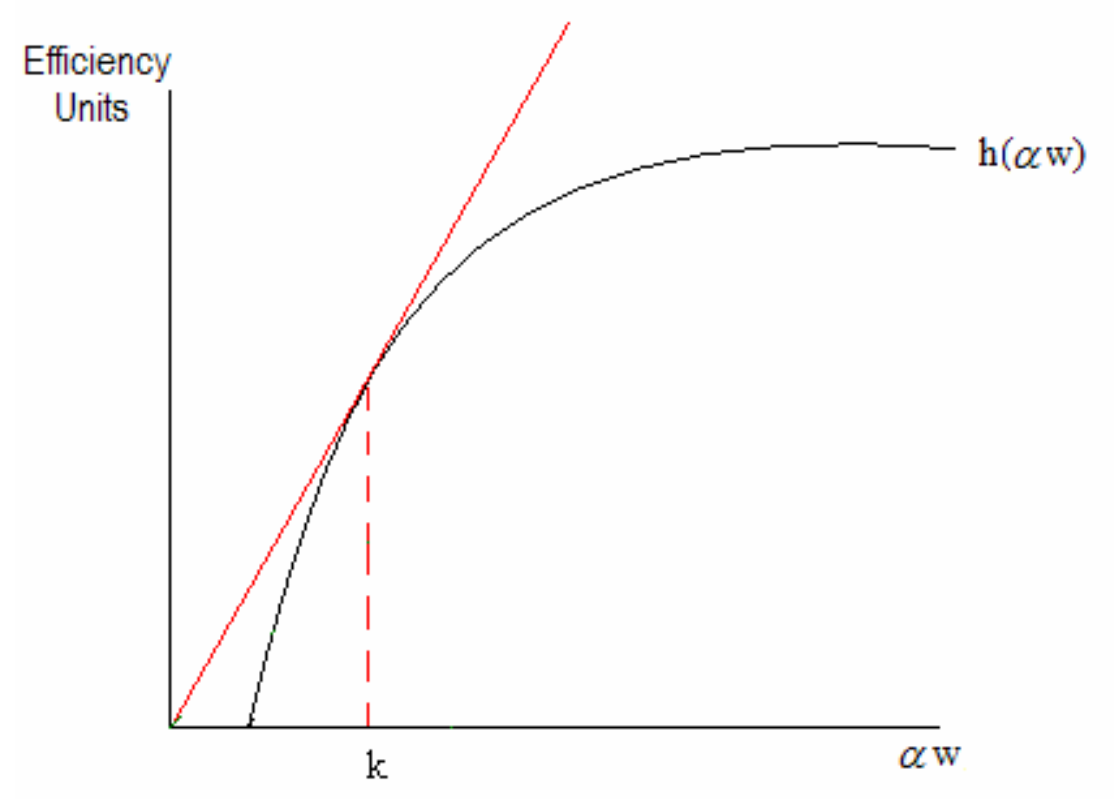

Figure 1 
If we insert this in (6) and solve for $n$, we get $n(\alpha)$. Hence, the constrained solution of this firm’s optimization is given by: $w(\alpha)$ and $n(\alpha)$. An ' $\alpha$-quasiequilibrium' is basically a wage rate which is equal to $w(\alpha)$ and aggregate labor supply that exceeds aggregate labor demand or a wage such that demand for labor equals supply of labor and no firm can do better by raising the wage.

Hence, in case $m n(\alpha) \leq N$, we have an $\alpha$-quasi-equilibrium in which all firms pay a wage of $w(\alpha)$ and demand $n(\alpha)$ and there is open unemployment equal to $N-m n(\alpha)$. If we had fixed $\alpha=1$, then this $\alpha$-quasi-equilibrium is exactly the equilibrium described by Leibenstein (1957), Mirrlees (1975) or Stiglitz (1976).

In case $m n(\alpha)>N$, then clearly firms paying a wage of $w(\alpha)$ and employing $n(\alpha)$ is not feasible. There will be excess demand for labor and this will drive the wage up. What will the wage be? To answer this, assume each firm takes the wage rate, $w$, as given. With $w$ and $\alpha$ as given, the number of workers a firm will demand is clearly given by equation (6). Write this solution as

$$
n=\tilde{n}(\alpha, w)
$$

The wage rate $w^{*}$ is an $\alpha$-quasi-equilibrium if $m \tilde{n}\left(\alpha, w^{*}\right)=N$. This means that if the wage is left to be determined endogenously by the forces of demand and supply, the wage will settle at $w^{*}$ and there will be no unemployment. ${ }^{5}$ Since the efficiency wage is below $w^{*}$ each firm will want to pay a lower wage but in that case demand will exceed supply and wage will rise to $w^{*}$.

\footnotetext{
${ }^{5}$ If an individual firm offers a wage below $w^{*}$, no worker will come to the firm; and offering a wage above $w^{*}$ makes no sense since the firm can hire any number of workers it wants at $w^{*}$, and $w^{*}$ is above the efficiency wage.
} 
Two alternative $\alpha$-quasi-equilibria, for $\alpha=\alpha_{0}$ and $\alpha_{1}$ are illustrated in Fig. 2. In both these cases there is open unemployment in equilibrium. Note that $\alpha_{1}<\alpha_{0}$ and $U_{1}>U_{0}$-more sharing yields a higher level of unemployment.

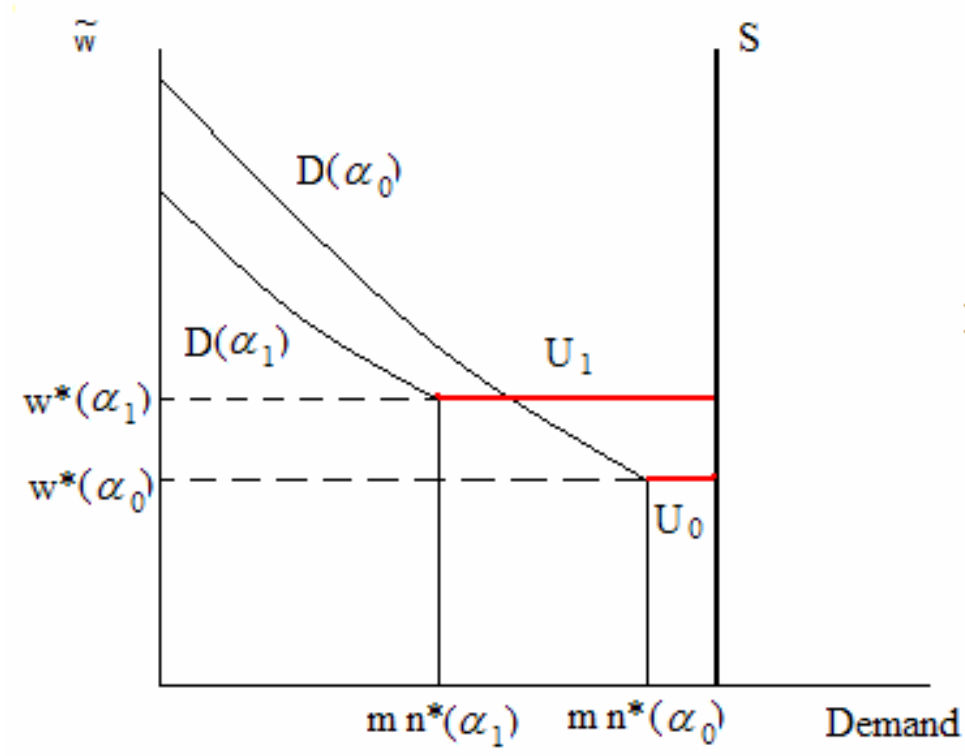

Figure 2

\subsection{The Full Competitive Equilibrium}

A (full) competitive equilibrium is now easy to define. Informally speaking, it is given by an $\alpha^{*}$ such that the $\alpha^{*}$-quasi-equilibrium 'corroborates' the $\alpha^{*}$.

It is easy to see that, given any $\alpha$, in the $\alpha$-quasi-equilibrium there will be a certain unemployment rate. Let this be denoted by $U(\alpha)$. Suppose there is open unemployment in the $\alpha$-quasi-equilibrium. In that case $U(\alpha)$ is defined as follows:

$$
U(\alpha)=\frac{N-m n(\alpha)}{N}
$$

And, in case $N<m n(\alpha)$, then $U(\alpha)=0$. 
Now for a formal definition: $\alpha^{*}$ and $U^{*}$ constitute a competitive equilibrium if $U^{*}=U\left(\alpha^{*}\right)$ and $\alpha^{*}=\alpha\left(U^{*}\right)$.

This is essentially a rational-expectations equilibrium. If all firms assume $\alpha$ to be $\alpha^{*}$ and this in turn gives rise to $U$ that corroborates the $\alpha^{*}$, then we have a competitive equilibrium.

The values of $\alpha, n, w$ and $U$ that occur in a competitive equilibrium will be denoted by $\alpha^{*}, n^{*}, w^{*}$ and $U^{*}$.

We will show that this model can have multiple competitive equilibria with different wages and levels of unemployment.

To see this, it is important for us to establish an initial result.

Lemma 1: $\quad$ As $\alpha$ increases, $n$ increases.

Proof: From the representative firm's profit maximizing first order conditions, (5) and (6) we know

$$
\alpha w h^{\prime}(\alpha w)=h(\alpha w)
$$

which is, essentially (7) rearranged. Since $\alpha$ and $w$ only appear as $\alpha w$ in (10), it follows that $\alpha w$ is constant. Let us write this as

$$
w(\alpha)=\frac{k}{\alpha},
$$

It follows that $w^{\prime}(\alpha)<0$. Substituting (11) into (5) we get $f^{\prime}(n h(k)) h^{\prime}(k) \alpha=1$ or

$$
f^{\prime}(n h(k))=\frac{1}{h^{\prime}(k) \alpha}
$$

Since $k$ is a constant, as $\alpha$ increases $f^{\prime}(n h(k))$ must fall. Given $f^{\prime \prime}<0$, it follows that $n$ must increase. 
Lemma 1 in conjunction with (9) implies that as long as $U(\alpha)>0$, as $\alpha$ increases $U(\alpha)$ will fall. Hence, $U(\alpha)$ and $\alpha(U)$, as defined, both have negative slopes. Therefore, it is entirely possible that they intersect more than once and the economy has multiple competitive equilibria. Figure 3 illustrates a possible case. ${ }^{6}$

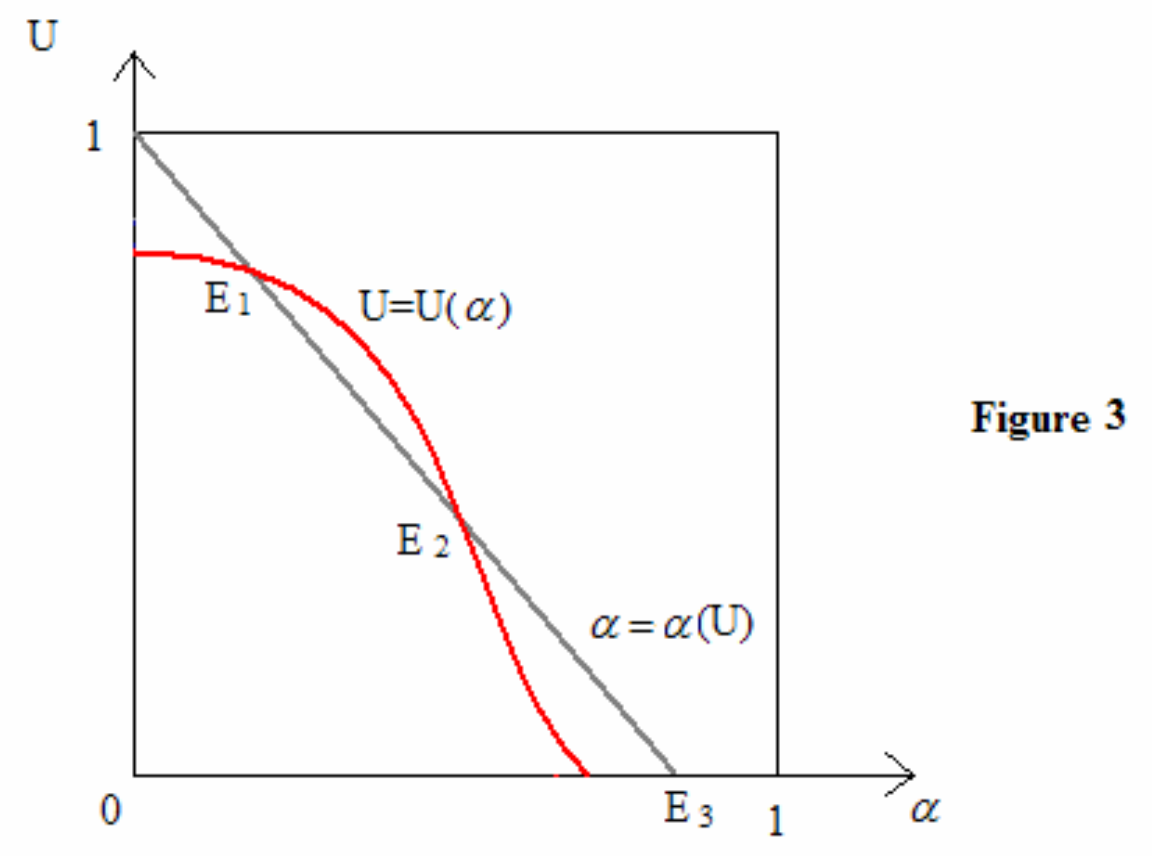

The economy illustrated in Fig. 3 has three possible equilibria, $E_{1}, E_{2}$ and $E_{3}$. Unemployment is highest at $E_{1}$ and lowest at $E_{3}$. Hence, the same economy can be caught in one equilibrium that has high unemployment and another equilibrium that has low unemployment.

Lemma 1 has an important implication about the relation between different possible competitive equilibria of an economy. If unemployment is positive in each of

\footnotetext{
${ }^{6}$ Since, when $U=1$, the question of $\alpha$ does not arise, the graph should be thought of as defined on the half open interval $\alpha \in(0,1]$.
} 
the possible equilibria, then the lower unemployment will invariably be associated with a lower wage as the standard model with legislatively fixed wages would imply. If however one of the equilibria involves full-employment (i.e. zero unemployment) this equilibrium can be associated with a higher wage than the other equilibria as we will demonstrate in the next section.

Our model can also help us understand another widely-observed phenomenon, namely that unemployment rates often differ between ethnic groups within the same country. ${ }^{7}$ This could happen if each sharing community is entirely a subset of one ethnic group and if each person's ethnic identity is easy to observe as would happen with the Blacks and Whites in South Africa, for instance. In one group, characterized by a high rate of unemployment, workers will have a greater propensity to share their income rather than to consume it themselves. This fact will lead them to be relatively less productive compared to workers from a community with a rather low rate of unemployment and little need for income sharing. Firms will prefer to hire those from the community with a low rate of unemployment thereby corroborating the fact of low unemployment.

Hence, two geographically neighboring communities could find themselves in vastly different labor market equilibria with different race specific employment rates. This idea is elaborated on at the end of the next section.

\footnotetext{
${ }^{7}$ Barring some non-generic exceptions, what the theory would suggest for economies with integrated labor markets is that either one group will have zero unemployment while the other has positive unemployment or one group will have total unemployment (that is, no demand for its labor) with the other group having higher wages and some unemployment. The claim can be made more general by introducing some frictional unemployment or the existence of some sector-specific firms. These ideas are elaborated upon below in this and the next sections.
} 


\section{A Paradoxical Result with Implications for Minimum Wage Legislation and Racial Dichotomies in Labor Markets}

The intriguing question that we raised earlier is: Is it possible for a country to have two equilibria one with full employment and high wage and another with larger (and therefore positive) unemployment and a lower wage? The answer to this question turns out to be yes, and this section is devoted to proving this. This has very interesting implications for minimum wage policy and understanding labor market schisms within a society, such as South Africa's. We comment on these at the end of the section and in the next section. Our first task is to demonstrate that the answer to the above question is yes. We do this by constructing an example. As one works through the example it will be obvious that it is not a non-generic special case but one illustration from a class of parameters where this pathology can occur.

Consider an economy with 120 laborers who supply their labor inelastically, as long as wage is non-negative. Hence $\mathrm{N}=120$. The economy has 10 identical firms, each endowed with the following production function

$$
x=f(H)=\frac{5}{2} H-\frac{1}{36} H^{2},
$$

where, as before, $H$ is the total amount of efficiency units employed by the firm. It follows that the marginal production function is give by:

$$
f^{\prime}(H)=\frac{5}{2}-\frac{H}{18}
$$

Let the labor efficiency function (that is (2) above) be given by: 


$$
h(c)=\left\{\begin{array}{ccc}
0 & \text { if } & c<\frac{1}{2} \\
-1+2 c & \text { if } & \frac{1}{2} \leq c<1 . \\
\frac{1}{2}+\frac{c}{2} & \text { if } & c \geq 1
\end{array}\right.
$$

This is illustrated in Fig. 4 by the line ABC.

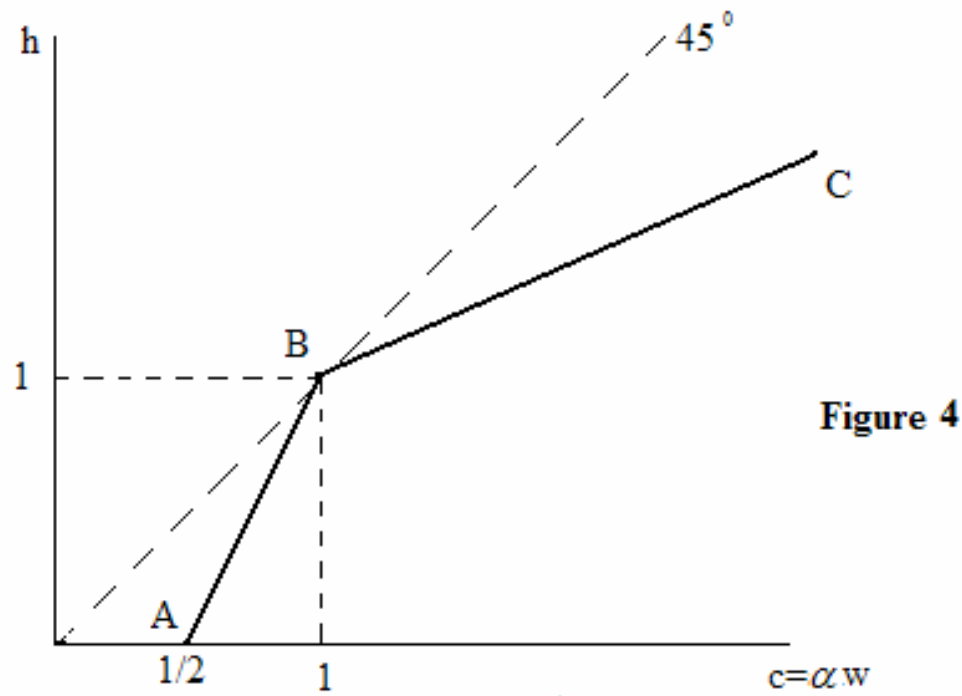

As currently described, $h$ is unbounded. We can rectify this by setting an upper bound on it and have the result unchanged.

Being non-differentiable (a harmless assumption made for algebraic convenience) we cannot determine the employer's optimal $c$ by differentiating the $h$-function but it is obvious on inspection that the cost of efficiency units of labor is minimized at $c=1$. Hence, the employer, faced with an $\alpha$, would ideally set

$$
w=\frac{1}{\alpha} .
$$

Hence, the efficiency wage is given by this formula. 
Given $\alpha$ and $w$, if we want to find out the number of laborers demanded by a firm, we can use (6) above. Adapting this, by using (13) we get

$$
\frac{5}{2}-\frac{n h(\alpha w)}{18}=\frac{w}{h(\alpha w)}
$$

Consider a special case where $\alpha=\frac{1}{2}$. Then $w=2$ and $h(\alpha w)=1$. Hence we can solve (16) and get $n=9$.

Since there are 10 firms, the aggregate demand for labor would be 90 and the unemployment rate is $(120-90) / 120=1 / 4$ or $25 \%$.

Consider now the case where $\alpha=\frac{2}{3}$. It is easy to verify that if firms were free to pay the efficiency wage, aggregate labor demand (180) would exceed labor supply. Hence, in equilibrium firms will be forced to pay a wage above the efficiency wage. One can further check that if with $\alpha=1$, wage was fixed for each firm at 2, each firm's demand for labor would exceed 12. Hence aggregate demand for labor would exceed $120=N$. Hence the market clearing wage will exceed 2 .

The numbers just derived are illustrated in Fig. 5, where the vertical axis represents the reservation wage faced by each firm (i.e. each firm is free to give a wage equal to or exceeding the point represented on the vertical axis) and the horizontal axis represents aggregate labor supply and demand. 


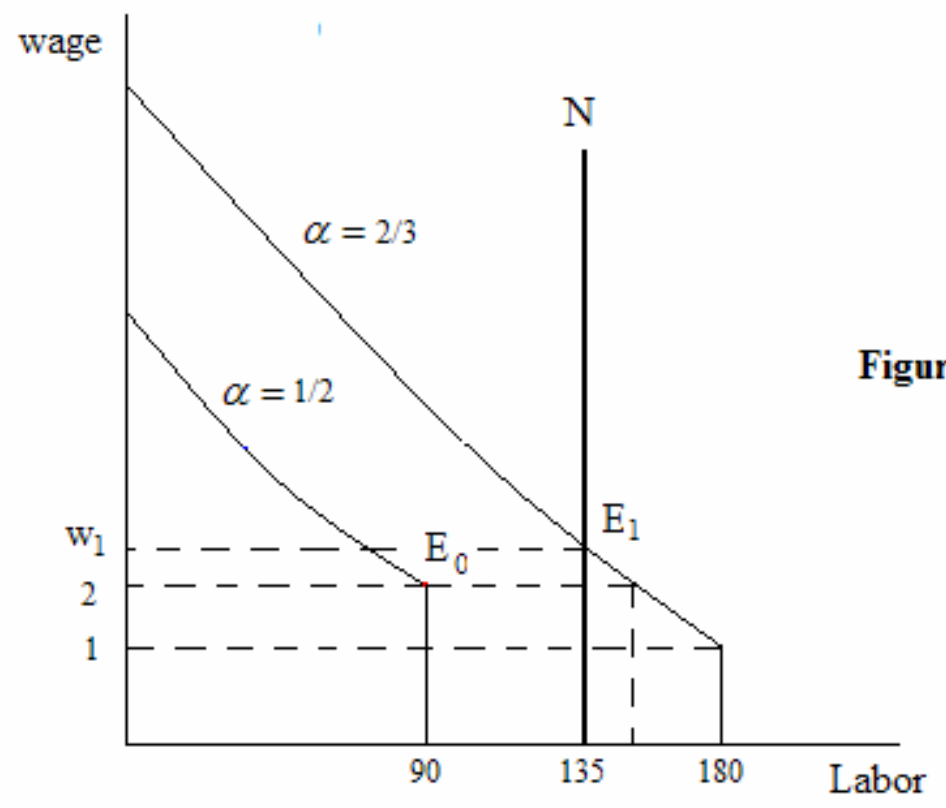

Hence, if $\alpha$ were $\frac{1}{2}$, equilibrium would be depicted by the point $E_{0}$ and if $\alpha$ were $\frac{2}{3}$, equilibrium would be depicted by the point $E_{1}$. These are, of course, $\alpha$-quasiequilibria. To see what $\alpha$ will prevail in the general competitive equilibrium we need to know what the economy's $\alpha$-function (i.e. (1), above) is like. Assume that $t=2, d=2$ and $\delta=\frac{1}{2}$. Hence,

$$
\alpha=\alpha(U)=(1-U) \frac{2}{3}
$$

where $U$ is the unemployment rate.

Figure 6 depicts this in the $(U, \alpha)$-space as in Fig. 1. 


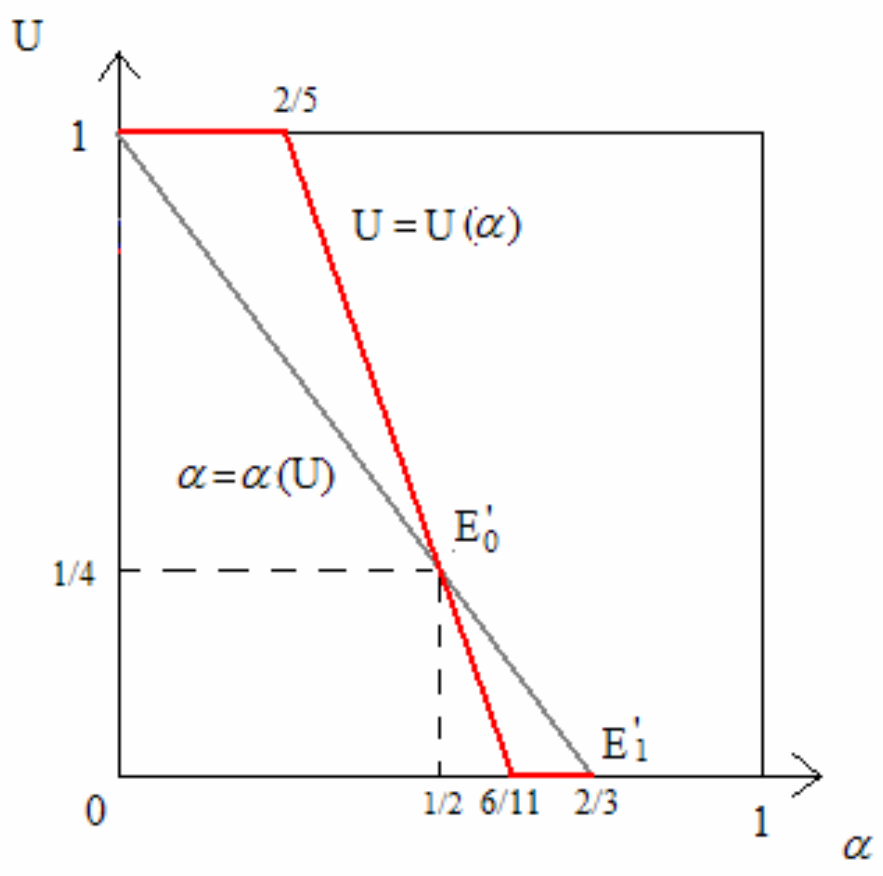

\section{Figure 6}

Given the economy described in this example, we can work out the unemployment rate that will occur given each value of $\alpha$. We can describe this as $U(\alpha)$. We already know that $U\left(\frac{1}{2}\right)=\frac{1}{4}$ and $U\left(\frac{2}{3}\right)=0$.

Since $\alpha\left(\frac{1}{4}\right)=\frac{1}{2}$ and $\alpha(0)=\frac{2}{3}$, we have a competitive equilibrium where $\alpha=\frac{1}{2}$, $U=\frac{1}{4}$ and $w=2$ and another competitive equilibrium where $\alpha=\frac{2}{3}, U=0$ and $w>2$.

This establishes the result we set out to prove. ${ }^{8}$

This result opens up the possibility of unconventional policy interventions.

Consider the economy described in this example and suppose it is at the equilibrium

\footnotetext{
${ }^{8}$ It is interesting to contrast this result with that of Shapiro and Stiglitz (1984), where higher unemployment is associated with greater worker efficiency. Of course, the assumptions behind that model were different. Our relatively counter-intuitive result calls for future empirical inquiry.
} 
described by $E_{0}^{\prime}$ in Fig. 6 . This corresponds to the point $E_{0}$ in Fig. 5 . So wage is at 2 and unemployment is at 30. Now suppose government imposes a statutory minimum wage, $w_{\min }$, where $2<w_{\min } \leq w_{1}$, where $w_{1}$ is described in the figure.

This immediately means that the economy can no longer be at $E_{0}$ and the equilibrium goes to $E_{1}$, where not only is wage higher (as would happen given any binding minimum wage law) but unemployment is lower. So a minimum wage law can lower unemployment. ${ }^{9}$ A similar result is known from standard textbook models where the labor market is monopolistic or oligopolistic. What is interesting about our paper is that this happens in a competitive model.

The above exercise was done in a static setting. There are important questions pertaining to dynamics. Once a minimum wage is imposed if productivity of workers does not respond quickly it may lead to two classes of workers-those who find highpaid jobs and become more productive and those who lose their jobs and find their productive powers eroding rapidly. This can give rise to interesting possibilities but we refrain from going into them in the present paper.

The result established in this section also helps us understand a real-world phenomenon mentioned above, where two ethnic groups exhibit very different labor market outcomes, more than can be explained in terms of differences in human capital or preference for leisure. In South Africa, observers have been baffled by the fact that, despite apartheid being abolished, the unemployment rate is so much higher for Blacks than for Whites. Moreover, as discussed above, all evidence suggests that despite this, Whites command a higher average wage than Blacks. The question arises about why an

\footnotetext{
${ }^{9}$ It is worth cautioning that in a different class of models (e.g., Basu et al., 2003) a minimum wage law can bring new equilibria into existence.
} 
employer does not replace his high-wage White workforce with Blacks, who will accept a lower wage and increase profits.

This is such an important and widespread phenomenon that there will no doubt be many different explanations of it. Our model points to an interesting possibility. Suppose the sharing of wages occur within racial group. That is, each group or community within which people support and insure one another consists of a subset of a single race. This does not seem to be an unrealistic assumption. If the sharing occurs within each household and households are racially homogeneous then this would be true. Assume also, for simplicity, that firms are sector-specific. For instance, there is an exogenously given number of firms in Soweto and these employ only Blacks. And the firms in Sandton employ only Whites. Now, if Blacks and Whites have different sharing norms (that is, given the same unemployment rate, $\alpha_{W} \neq \alpha_{B}$ ) then the two groups could settle into different rates of unemployment and wages. What is even more interesting is that, even if both groups are identical in every way, including their sharing norms, they can, in equilibrium, have different unemployment rates and wages. Of course, which equilibrium one settles into may have a lot to do with history and the divisions of history are of course especially deep for Whites and Blacks in South Africa. But this is fully compatible with the existence of multiple equilibria.

The above argument makes use of the assumption that firms are sector-specific, that is, there is an exogenously given set of firms that operate where Blacks live and another exogenously given set of firms where Whites live. If firms are free to move from one sector to another then the analysis gets more complicated. Market schism would still occur but one of the groups (say Whites) would have full employment whereas the other 
could have large unemployment. In addition, as we have just shown, wages could be lower in the sector that has large unemployment, pretty much in keeping with the experience of South Africa.

Following the same kind of reasoning another kind of dichotomy of the labor market that can arise in a fully integrated labor market is easy to understand. Persisting with the assumption of intra-group sharing consider a case where Blacks have higher unemployment than Whites and therefore lower $\alpha$. Clearly firms will prefer to employ Whites. One stopping point of this is where Blacks wages are driven down so low that Black unemployment is total whereas White wage rises to efficiency level with some positive unemployment. Of course reality does not match this polar extreme. But once we combine this model with the fact that there will always be some sector-specific firms in reality and also that a large fraction of the Blacks in South Africa who are employed are actually self-employed, it becomes evident that our model may contain significant insights into the stark dichotomies that one sees in some economies such as that of South Africa.

\section{Using Subsidies to Curb Unemployment}

Let us consider a government whose goal is to decrease unemployment and it has some funds available to use as subsidies to induce firms to employ more people. The existence of multiple equilibria means that a government seeking to decrease unemployment permanently need simply decrease unemployment sufficiently in one period to create a permanent change in the unemployment level. This one period decline in unemployment will decrease the amount of community based sharing, by the fact that there are fewer unemployed people with which one should share, and make labor more productive, in 
terms of efficiency units, to firms. The increase in the productivity of labor due to less sharing will lead to the hiring of more workers and reinforce both the lower levels of sharing and unemployment in the labor market. Given the effect of the one period government intervention is large enough, the economy will settle at a new equilibrium. Government policy that could deflect a high-unemployment-economy into a new labor market equilibrium with lower unemployment could consist of minimum wage legislation, a subsidy on output or a one time per worker subsidy to firms. Minimum wage legislation has been addressed previously and this section will be devoted to the effects of the latter two interventions.

\subsection{Output Subsidy}

Let us begin by considering an output subsidy. When the government provides an output subsidy the firm's profit is as follows.

$$
\pi(n, w)=(1+s) f(n h(\alpha w))-n w
$$

This profit function incorporates the fact that firms now receive a price $(1+s)$ for each unit of output produced, where $s$ represents the amount of the output subsidy. The first order conditions are:

$$
\begin{aligned}
& (1+s)\left[f^{\prime}\left(n^{*} h\left(\alpha w^{*}\right)\right) h^{\prime}\left(\alpha w^{*}\right) \alpha\right]-1 \equiv 0 \\
& (1+s)\left[f^{\prime}\left(n^{*} h\left(\alpha w^{*}\right)\right) h\left(\alpha w^{*}\right)\right]-w^{*} \equiv 0 .
\end{aligned}
$$

It is easy to see (19) and (20) again give us equation (7). It follows that changes in $s$ leave $w$ unchanged, assuming, for now, that $\alpha$ is fixed.

Next note that (20) can be rewritten as

$$
(1+s) f^{\prime}\left(n^{*} h\left(\alpha w^{*}\right)\right)=\frac{w^{*}}{h\left(\alpha w^{*}\right)}
$$


If $s$ increases, since we know $w^{*}$ is unchanged, it follows that $n^{*}$ must rise, since $f^{\prime \prime}<0$. Hence we have established $\frac{\partial w^{*}}{\partial s}=0$ and $\frac{\partial n^{*}}{\partial s}>0$.

This is not the end of the analysis since we have been assuming $\alpha$ constant as $s$ changes. In the full competitive equilibrium this need not be the case. To see this suppose $s$ rises (we could consider the case where $s$ goes from 0 to some positive number). From what we have already established we know that each firm will demand more labor. Hence, the curve representing $U(\alpha)$ in Fig. 3 will move down (as employment increases, unemployment falls). What happens to the competitive equilibrium will depend on which of the several equilibria- $E_{1}, E_{2}, E_{3}$ - the economy happened to be in to start with. If it were $E_{2}, \alpha$ would fall and, surprisingly, unemployment, $U$, will rise. The wage will also rise, since $\alpha w$ is constant.

But $E_{2}$ is an unstable equilibrium, and therefore less important in reality. Let us see what happens from $E_{1}$ and $E_{3}$. If the economy were at $E_{1}$ and government gives a production subsidy $s(>0)$, it is obvious from Fig. 3 that unemployment will fall and $\alpha$ will rise. Hence, the wage rate will decline. This is an interesting result, and contrary to what is obtained in a standard neoclassical labor market model. A policy that raises the demand for labor causes the wage to decline. The intuition behind this is illustrated by Fig. 2.

Finally, if the economy was at $E_{3}$, then, since unemployment is zero to start with, a rise in $s$ will leave unemployment unchanged. The rise in demand for labor will simply cause wage (which in this case is above the efficiency wage level) to rise. 
To see how a one-time policy intervention can deflect the economy to a different equilibrium that we discussed earlier, suppose, to start with, the economy is at $E_{1}$. As a subsidy $s$ is given and steadily increased the $U(\alpha)$ curve moves down. With that $E_{1}$ and $E_{2}$ move closer to each other. Beyond a critical level of $s$, the equilibria $E_{1}$ and $E_{2}$ cease to exist. The only intersection between the $U(\alpha)$ and $\alpha(U)$ graphs in Figure 3 occurs at $E_{3}$. So as $s$ is raised, the labor market at some point will get deflected to the full-employment equilibrium, $E_{3}$. So a policy of subsidy for a short period, after which the subsidy is withdrawn, can cause a permanent drop in unemployment.

\subsection{Wage Subsidy}

Next, let us consider a government provided per-worker subsidy. This is a fairly transparent policy intervention, which is meant to be a direct incentive to firms to hire more workers and cut down unemployment. When the government provides a per worker subsidy the firm's profit is as follows.

$$
\pi(n, w)=f(n h(\alpha w))-n(w-s)
$$

This makes the effective wage the firm pays $(w-s)$ because the government covers part of the firms wage bill—s per worker—in the form of a subsidy to the firm. The first order conditions to this profit maximization problem are

$$
\begin{aligned}
& f^{\prime}\left(n * h\left(\alpha w^{*}\right)\right) h^{\prime}\left(\alpha w^{*}\right) \alpha-1 \equiv 0 \\
& f^{\prime}\left(n * h\left(\alpha w^{*}\right)\right) h\left(\alpha w^{*}\right)-w^{*}+s \equiv 0 .
\end{aligned}
$$

The optimal wage and number of workers employed are both a function of the amount of sharing and the government's subsidy $-n *(\alpha, s)$ and $w^{*}(\alpha, s)$. To 
determine the effect of the subsidy differentiate the first order conditions with respect to s. This yields the following system.

$$
\left[\begin{array}{cc}
f^{\prime} \alpha^{2} h^{\prime \prime}+h^{\prime 2} f^{\prime \prime} \alpha^{2} n^{*} & h^{\prime} \alpha f^{\prime \prime} h \\
f^{\prime} h^{\prime} \alpha+h n^{*} f^{\prime \prime} h^{\prime} \alpha-1 & h^{2} f^{\prime \prime}
\end{array}\right]\left[\begin{array}{c}
\frac{\partial w^{*}}{\partial s} \\
\frac{\partial n^{*}}{\partial s}
\end{array}\right] \equiv\left[\begin{array}{c}
0 \\
-1
\end{array}\right]
$$

By applying Cramer's Rule we find $\frac{\partial w^{*}}{\partial s}<0$ and $\frac{\partial n^{*}}{\partial s}>0$. The government is essentially paying the firm to hire more workers. By paying the subsidy per worker the firm only gets the benefit of $s$ when they add an additional worker. An increase in $s$ leads directly to an increase in the optimal amount of workers employed by the firm. If the government subsidizes the wage bill of firms in such a way that the total subsidy paid to the firm increases with the number of workers hired then labor will be effectively cheaper for firms and they will hire more of workers.

Like before, to complete the analysis we have to go from this study of $\alpha$ equilibrium to the full-competitive equilibrium. The analysis is similar to what was conducted above and so will not be repeated. The result is, that just like an output subsidy, a per-worker subsidy given for a short period and then withdrawn can cause a permanent drop in unemployment.

Again, the multiple equilibria result established in section 3 dictates that this subsidy need not be persistent. The government has the ability to deflect the labor market into a high-employment equilibrium with a one time intervention that increases the demand for labor and reduces sharing in that period. The magnitude required for such a 
subsidy to be successful depends on the amount of current sharing within the community and consequently on the current unemployment level.

\section{Conclusion}

We have shown that there can be multiple equilibria in a labor market if firms act according to the standard efficiency wage theory and, in addition, laborers share part of their income with the unemployed members of their community. The equilibria differ in their levels of unemployment and income sharing — an equilibrium with high unemployment will be supported by a high level of sharing which, in turn, reinforces the high unemployment, and an equilibrium with low or no unemployment will yield a small amount of income sharing and this will reinforce the low unemployment.

The analysis leads to natural policy questions such as: Can we cause an equilibrium to shift so that unemployment becomes lower? Can we actually shift an economy from the high unemployment equilibrium to the low unemployment equilibrium? Are there policies that can alter the equilibrium wage? A variety of interventions were studied in the paper, from minimum wage laws to subsidizing firms in different ways to induce them to demand more labor. We obtained results that are expected but also some that are surprising.

There is scope for discussing many other policies using the model developed in the paper. One natural candidate is the use of unemployment dole or welfare for those out of jobs. Without going into full details note that, if the government were to announce an unemployment subsidy to the unemployed persons, then income sharing in the economy would decrease because there would not be as much need for the employed to support those who are out of work. Hence, laborers, who would now be consuming a 
larger portion of their own wages, would become more valuable in the production process. Firms would thereby increase their employment of labor and hire from the pool of unemployed. This would decrease the unemployment rate in the community. So it seems arguable that the actual subsidy the government would have to dole out would not be as large as it would have appeared when the subsidy was first announced. Moreover, it is possible that in response to the intervention the economy moves to a situation, which was an equilibrium (with lower unemployment) of the original economy. If this happens, then the subsidy can eventually be removed and we could still have the economy remain at the low unemployment equilibrium.

Less apparent policies that can be discussed using this model are in the realm of family planning and fertility policy. Lemma 1 has an interesting implication about the relation between fertility and unemployment. Note that a society with lower fertility has a lower $d$. Hence, by equation 1, a society with lower fertility will have a higher $\alpha$. By Lemma 1 , such a society will have a higher demand for labor. Interesting questions arise if we treat fertility as a choice variable, something that is decided by a process of negotiation within the household (Strauss and Thomas, 1995; Bardhan and Udry, 1999), instead of being exogenously fixed, as assumed here. Households can then have fewer children and signal their higher $\alpha$. Governments could also use this argument to justify certain interventions concerning family size. This is a matter deserving of future investigation.

Finally, in the spirit of what we have already seen above, one can use a minimum wage law not for perennially holding up the wages but to deflect the economy to a preexisting equilibrium, akin to what was derived in Basu (2000) in the context of child 
labor. Basically, unlike more conventional labor market interventions, the model we have creates the scope for interventions which can be a one-time measure to deflect the economy from one equilibrium to another, more-desirable equilibrium. The idea of the paper was to outline a model which opens up the possibility of more systematic research into these kinds of unusual 'transitory' policy interventions for tackling the problem of unemployment.

What is particularly interesting is that a zero-unemployment equilibrium could have a higher market wage for labor than the high unemployment equilibrium. If shortterm government intervention is effective in shifting the economy from high unemployment to zero unemployment, the reduction in income sharing brought about by this could increase the demand for labor so much that it exceeds the supply of labor and the new outcome is sustained as an equilibrium, with no further government intervention needed. Firms are compelled by natural market forces to operate according to the reservation wage, which is above the efficiency wage, and so end up paying higher wages and employing more people. This contradicts the notion that, in a competitive labor market, a legislative intervention that raises wages does so only by increasing unemployment. 


\section{REFERENCES}

Agarwala, N. (1979) On Leibenstein's Theory of Disguised Unemployment, Indian Economic Review, 14, 29-42.

Aghion, P. and Blanchard, O. (1994) On the Speed of Transition in Central Europe, in S. Fischer and J. Rotemberg (eds.) NBER Macroeconomic Annual, The MIT Press , Cambridge, MA.

Aghion, P., Blanchard, O., and Burgess, R. (1994) The Behavior of State Firms in Eastern Europe Pre-Privatization, Eastern European Economic Review, 38, 132749.

Bardhan, P. (1980) Interlocking Factor Markets and Agrarian Development, Oxford Economic Papers, 32, 82-98.

Bardhan, P. and Udry, C. (1999), Development Microeconomics, Oxford University Press, Oxford.

Basu, K. (1993) Efficiency wage theory with monopolistic landlords, in K. Basu, M. Majumdar, and T. Mitra (eds.) Capital, Investment, and Development: Essays in Memory of Sukhamoy Chakravarty. Blackwell Press, Oxford.

Basu, K. (1997) Analytical Development Economics: The Less Developed Economy Revisited. The MIT Press , Cambridge, MA.

Basu, K. (2000) The Intriguing Relation between Adult Minimum Wage and Child Labour, Economic Journal, 110, 50-61.

Basu, K. (2006) Gender and Say: A Model of Household Behavior with Endogenously Determined Balance of Power, Economic Journal, 116, 558-80.

Basu, K., Genicot, G., and Stiglitz, J. (2003) Minimum Wage Laws and Unemployment Benefits, in K. Basu, P.B. Nayak and D. Ray (eds.) Markets and Governments, Oxford University Press, New Delhi.

Bliss, C. and Stern, N. (1978) Productivity, wages and nutrition: 1. The theory; 2. Some observations, Journal of Development Economic, 5, 363-98.

Casale, D., Muller C., and Posel D. (2004) 'Two Million Net New Jobs': A Reconsideration of the Rise in Employment in South Africa? Mimeo: University of KwaZulu-Natal.

Cashdan, E. (1985) Coping with Risk: Reciprocity Among the Basarwa of Northern Botswana, Man, New Series, 20, 454-74. 
Cox, D., Eser, Z., and Jimenez, E. (1998) Motives for Private Transfers Over the Life Cycle: An analytical framework and evidence for Peru, Journal of Development Economics, 55, 57-80.

Dasgupta, P. and Ray, D. (1986) Inequality as a determinant of malnutrition and unemployment, Economic Journal, 96, 1011-34.

Dasgupta, P. and Ray, D. (1987) Inequality as a Determinant of Malnutrition and Unemployment, II. Policy, Economic Journal, 97, 1011-34.

Dasgupta, P. and Ray, D. (1990) Adapting to undernourishment: The biological evidence and its implications, in J. Dreze and A. Sen (eds.), The Political Economy of Hunger, vol. 1. Clarendon Press, Oxford.

Evans-Pritchard, E. (1940) The Nuer: A description of the Modes of Livelihood and Political Institutions of a Nilotic People, Clarendon Press , Oxford.

Fafchamps, M. (1992) Solidarity Networks in Preindustrial Societies: Rational Peasants with a Moral Economy, Economic Development and Cultural Change, 41, 14774.

Fafchamps, M. and Lund, S. (2003) Risk Sharing Networks in Rural Philippines, Journal of Development Economics, 71, 261-87.

Genicot, G. (2005) Malnutrition and Child Labor, Scandinavian Journal of Economics, 107, 83-102.

Guha, A. (1989) Consumption, efficiency and surplus labour, Journal of Development Economics, 31, 1-12.

Hoff, K. and Sen, A. (2006) The Kin System as a Poverty Trap, in S. Bowles, S. Durlauf and K. Hoff (eds.), Poverty Traps, Princeton University Press, Princeton, NJ.

Kent, S. (1993) Sharing in an Egalitarian Kalahari Comminity, Man, New Series, 28, 479-514.

Kochar, A. (2000) Parental Benefits from Intergenerational Coresidence: Empirical Evidence from Rural Pakistan, Journal of Political Economy, 108, 1184-209.

Leibenstein, H. (1957) The Theory of Underemployment in Backward Economies, Journal of Political Economy, 65, 91-103.

Leibenstein, H. (1958) Underemployment in Backward Economies: Some Additional Notes, Journal of Political Economy, 66, 256-58. 
Leibrandt, M., van der Berg, S., and Bhorat, H. (2003) Inroductiton, in H. Bhorat et. al. (eds.), Fighting Poverty: Labour Markets and Inequality in South Africa, UCT Press, Lansdowne, South Africa.

Mazumdar, D. (1959) The Marginal Productivity Theory of Wages and Disguised Unemployment, Review of Economic Studies, 26, 190-97.

Mirrlees, J. (1975) Pure Theory of Underdeveloped Economies, in L. G. Reynolds (ed.), Agriculture in Development Theory, Yale University Press, New Haven.

Osmani, S. (1990) Nutrition and the Economics of food: Implications of some recent controversies, in J. Dreze and A. Sen (eds.), The Political Economy of Hunger, vol. 1, Clarendon Press, Oxford.

Platteau, J. (1997) Mutual Insurance as an Elusive Concept in Traditional Rural Communities, Journal of Development Studies, 33, 764-96.

Platteau, J. and Abraham, A. (1987) An Inquiry into Quasi-Credit Contracts: The Role of Reciprocal Credit and Interlinked Deals in Small-scale Fishing Communities, Journal of Development Studies, 23, 461-90.

Popkin, S. (1979) The Rational Peasant: the Political Economy of Rural Society in Vietnam, University of California Press, Berkeley.

Ravallion, M. and Dearden, L. (1988) Social Security in a 'Moral Economy': An Empirical Analysis for Java, Review of Economics and Statistics, 70, 36-44.

Ray, D. (1998) Development Economics. Princeton University Press, Princeton, NJ.

Rodgers, G. (1975) Nutritionally base wage determination in the low-income market, Oxford Economic Papers, 27, 61-81.

Scott, J. (1976) The Moral Economy of the Peasant, Yale University Press, New Haven.

Shapiro, C. and Stiglitz, J. (1984) Equilibrium Unemployment as a Worker Discipline Device, American Economic Review, 74, 433-44.

Stats SA (2003). Labour Force Surveys, Statistical Release P0210, Statistics South Africa, Pretoria, March 2003.

Stiglitz, J. (1976) The efficiency wage hypothesis, surplus labour and the distribution of labour in LDCs, Oxford Economic Papers, 28, 185-207.

Strauss, J. and Thomas, D. (1995) Human Resources: Empirical Modeling of Household and Family Decisions, in J. Behrman and T. N. Srinivasan (eds.), Handbook of Development Economics, vol. iii(A), Elsevier Science, Amsterdam. 
Townsend, R. (1994) Risk and Insurance in Village India, Econometrica, 62, 539-91. 